\title{
Primary Cancer Sites and Clinical Features of Choroidal Metastasis in Mexican Patients
}

This article was published in the following Dove Press journal: Clinical Ophthalmology

\author{
Guillermo Salcedo- \\ Villanueva, (D)' Abraham \\ Alejandro Medina-Andrade,' \\ Daniel Moreno-Paramo, ${ }^{2}$ Maria \\ Fernanda Golzarri,' Edel \\ Moreno-Paramo, (ID)' Grecia \\ Yael Ortiz-Ramirez, (D) 'Ursula \\ Martinez-Aguilar, ${ }^{3}$ Ulises De \\ Dios-Cuadras, ${ }^{3}$ Martin Jimenez- \\ Rodriguez, (iD ${ }^{4}$ Itzel Espinosa- \\ Soto, ${ }^{4}$ Ximena Mira-Lorenzo, ${ }^{5}$ \\ Juvenal Guzman-Cerda, ${ }^{5}$ Andres \\ Orozco-Moguel, ${ }^{6}$ Catalina \\ Becerra-Revollo, (ID) Luis \\ Porfirio Orozco-Gomez, ${ }^{7}$ \\ Emiliano Fulda ${ }^{3}$ \\ 'Retina Department, Asociación Para \\ Evitar la Ceguera en México, Hospital \\ "Dr. Luis Sánchez Bulnes", Mexico City, \\ Mexico; 'Ophthalmology Department, \\ Hospital General de México \\ "Dr. Eduardo Liceaga", Mexico City, \\ Mexico; ${ }^{3}$ Retina Department, Instituto de \\ Oftalmología Fundación Conde de \\ Valenciana, Mexico City, Mexico; ${ }^{4}$ Retina \\ Department, Fundación Hospital Nuestra \\ Señora de la Luz, Mexico City, Mexico; \\ ${ }^{5}$ Retina Department, Instituto Mexicano \\ de Oftalmología, Santiago de Queretaro, \\ Mexico; ${ }^{6}$ Facultad de Medicina, \\ Universidad Nacional Autónoma de \\ México, ${ }^{7}$ Retina Department, Centro \\ Médico Nacional 20 de Noviembre, \\ Mexico City, Mexico
}

Correspondence: Guillermo SalcedoVillanueva Retina

Department, Asociación Para Evitar la Ceguera en México, Hospital "Dr Luis

Sánchez Bulnes", IAP, Vicente García

Torres 46, Col. San Lucas, Coyoacan,

Mexico City, CP 04030, Mexico

Tel +52 55 10841400, Ext 1172

Email guillermo.salcedo@apec.com.mx
Purpose: To describe the primary cancer sites and clinical features of choroidal metastasis in Mexican patients.

Methods: This was a retrospective, observational, and multi-center study. Data were recollected from 6 ophthalmological hospitals in Mexico from patients with choroidal metastasis diagnosed from 2000 to 2018 .

Results: Seventy-eight patients were studied: 43 were female and 35 were male. Mean age at presentation was 57.6 years. Overall, primary cancer sites were: 1) breast: 27 cases $(34.6 \%)$; 2) lung: 19 cases $(24.3 \%)$; 3) unknown: 8 cases $(10.2 \%)$; 4 ) gastrointestinal: 7 cases $(8.9 \%)$; 5) renal: 5 cases $(6.4 \%)$; 6$)$ testicular: 3 cases $(3.8 \%)$; 7$)$ ovary: 3 Cases $(3.8 \%) ; 8)$ prostate: 2 cases $(2.5 \%)$; 9$)$ thyroid: 2 cases $(2.5 \%) ; 10)$ carcinoid: 1 case $(1.2 \%)$; and 11$)$ multiple myeloma: 1 case $(1.2 \%)$. Divided by gender, for women, the main three sites were: breast, unknown, and ovary. For men, the main three sites were: lung, gastrointestinal, and testicular. Oldest cases were breast cancer ( 87 and 85 years); youngest cases were testicular (23 and 25 years). Solitary lesions were observed in 56 cases $(71.7 \%$ ); multiple lesions were observed in 22 cases $(28.2 \%)$. Forty-two cases had a white or yellowish color, while 6 cases presented an orange color.

Conclusion: Primary cancer sites and clinical features of choroidal metastasis in Mexican patients show important differences from other populations previously studied, mainly the presence of a higher proportion of gastrointestinal and renal cancer, as well as higher incidence of ovarian and testicular cancer. These types of cancer, although not as common as breast or lung, need to be taken into account when studying Mexican patients living abroad.

Keywords: choroidal neoplasms, eye neoplasms, neoplasm metastasis, ovarian neoplasms, testicular neoplasms

\section{Introduction}

Cancer is one of the leading causes of death worldwide, with 18.1 million new cases and 9.6 million deaths during 2018. ${ }^{1-3}$ In Mexico, cancer is the third cause of death. ${ }^{4}$ The increasing cancer burden may be explained by different factors, such as population growth, better life expectancy, as well as an increase in the prevalence of causes of cancer linked to social and economic growth. ${ }^{3}$ Globally, cancer has distinct patterns that may depend on these last factors. Shifting populations due to worldwide migration can have an impact on the main types of cancer in a specific region.

Intraocular metastasis are classically considered to be the most common malignant tumors of the eye in adults. In the last decade there have been increasing 
reports for choroidal metastasis, from 29 to 56 publications in 2008 and 2018, respectively (Pubmed search using "choroidal metastasis"). Most of the metastasis are detected in the uveal tract, and among them, $88 \%$ are found in the choroid. ${ }^{5}$ Metastasis to the retina, optic nerve or vitreous humor are rare. ${ }^{6,7}$ Vascularization of the choroid and microenvironmental factors have been proposed as possible explanations for the high rate of metastasis to this part of the uveal tract. ${ }^{5}$ The diagnosis is usually clinical and can be supported by imaging studies such as ultrasound, fluorescein angiography (FA), fundus autofluorescence (FAF), and spectral-domain optical coherence tomography (SD-OCT), ${ }^{8,9}$ and in necessary cases, transvitreal, sub-retinal biopsy can be performed.

Even though choroidal metastasis are considered the most common intraocular malignant tumor in adults, the majority of published reports have been small, retrospective and isolated cases, with only a few large retrospective studies published since 1997: Shields et al, 1997, 520 cases; ${ }^{5}$ Kreusel et al, 2003, 71 cases; ${ }^{10}$ Soysal HG, 2007, 38 cases; ${ }^{11}$ and Shields et al, 2018, 1111 cases. ${ }^{12}$ Therefore, there is a lack of knowledge on the epidemiology of choroidal metastasis on different regions and populations, such as Latin America. Currently, world migration obligates the need to understand the epidemiology of diseases in different ethic groups and races, in order to increase the chance of a prompt and correct diagnosis. For example, Mexicans living in the United States of America make up 11.2\% of the country's entire population, with 36.3 million residents. ${ }^{13}$ Understanding the epidemiology of metastasis can prove useful in detecting unknown cancer in these patients. Many patients with this ocular condition do not have a previous history of cancer. ${ }^{5,10,12}$ Cancer detection and diagnosis has changed as imaging modalities have evolved throughout time. Previous studies date back to $1997,{ }^{5}$ $2003,{ }^{10}$ and $2007 .{ }^{11}$ Hence, it would be important to know if trends in cancer have changed throughout time, and if unknown cancer sites have decreased recently. By knowing how metastasis behave in a specific population one could detect the primary site of unknown cancer faster.

Therefore, the purpose of this study is to describe the primary cancer sites of choroidal metastasis, as well as the clinical spectrum of presentation in a cohort of Latin American patients studied in Mexico.

\section{Patients and Methods}

This is a retrospective, observational, and multi-center study. Data was recollected from 6 ophthalmological hospitals in Mexico: 1) Asociación Para Evitar la Ceguera en México (APEC); 2) Hospital General de México; 3) Fundación Hospital Nuestra Señora de la Luz; 4) Instituto Mexicano de Oftalmología; 5) Instituto de Oftalmología Fundación Conde de Valenciana; 6) Centro Médico Nacional 20 de Noviembre. The project had prior Institutional Review Board (IRB) approval (IRB at APEC), and was adherent to the tenants of the Declaration of Helsinki.

The medical records of adult patients with choroidal metastasis diagnosed from 2000 to 2018 were retrospectively reviewed. Complete ophthalmologic examination had been previously performed in all patients, including visual acuity (VA), intraocular pressure (IOP), anterior segment biomicroscopy, and fundus examination. Data analyzed included age, sex, presenting symptoms, type of primary tumor, laterality, number of lesions, clinical characteristics of the tumors, presence of retinal detachment (RD), treatment, and time between the diagnosis of cancer and the presentation of the choroidal metastasis. Suspicion of choroidal metastasis was based on clinical features previously reported. ${ }^{5}$ All patients underwent systematic evaluation and were treated in conjunction with the corresponding oncology department.

Data was recorded into spreadsheets using Numbers for Mac (Ver.3.6.2. Apple, Cupertino CA, USA). Descriptive statistics are described using central tendency measures. Distribution of the sample was determined using the Shapiro-Wilk test. One-way ANOVA and Tukey HSD post hoc testing were performed when analyzing multiple variables. Mann-Whitney U-test was used as a nonparametric test to compare means. Statistical analysis was performed with SPSS (Ver. 22. IBM Corp. Armonk, NY, USA). Statistical significance was considered as $\mathrm{P}<0.05$.

\section{Results}

A total of 78 patients were recruited from 6 institutions, of which 43 were female (55.1\%) and 35 were male (44.8\%). The mean age of presentation was 57.6 years, median: 59.5 years (standard deviation [SD] 14.51; range: 23-87 years). The overall results for primary cancer sites, as well as its segmentation by gender are shown in Tables 1 and 2 .

Segmentation of primary cancer site by age is shown in Table 3. Age presented a normal distribution, tested by the Shapiro-Wilk test $(\mathrm{P}=0.976)$. Ninety-five percent confidence intervals $(95 \% \mathrm{CI})$ for mean age resulted in 54.35 60.94 years. The eldest cases observed were: 1) breast, 2 
Table I Comparison of Primary Cancer Sites in Different Cohorts

\begin{tabular}{|c|c|c|c|c|}
\hline Rank & Current study & Shields et $\mathrm{al}^{12}(20 \mid 8)$ & Kreusel et al ${ }^{10}(2003)$ & Soysal HG' ' (2007) \\
\hline I & Breast: $27(34.6 \%)$ & Breast: 416 (37.4\%) & Breast: 38 (53\%) & Breast: 24 (85.7\%) \\
\hline 2 & Lung: 19 (24.3\%) & Lung: 295 (26.5\%) & Lung: 19 (26\%) & Lung: 2 (7.1\%) \\
\hline 3 & Unknown: 8 (I0.2\%) & Unknown: I77 (15.9\%) & Others: 6 (8\%) & Ovary: I (3.6\%) \\
\hline 4 & Gl: 7 (8.9\%) & Renal: 46 (4.1\%) & Renal: 2 (3\%) & GI: I (3.6\%) \\
\hline 5 & Renal: 5 (6.4\%) & Gl: 40 (3.6\%) & GI (Colon): 2 (3\%) & \\
\hline 6 & Testicular: 3 3.8\%) & Melanoma: 27 (2.4\%) & Melanoma: 2 (3\%) & \\
\hline 7 & Ovary: 3 (3.8\%) & Lung carcinoid: 24 (2.1\%) & Uveal melanoma: 2 (3\%) & \\
\hline 8 & Prostate: 2 (2.5\%) & Prostate: 23 (2.0\%) & Unknown: I (I\%) & \\
\hline 9 & Thyroid: 2 (2.5\%) & Thyroid: 15 (1.3\%) & & \\
\hline 10 & Lung carcinoid: I (I.2\%) & Pancreas: 8 (0.7\%) & & \\
\hline II & MM: I (I.2\%) & Others: 40 (3.6\%) & & \\
\hline
\end{tabular}

Abbreviations: $\mathrm{Gl}$, gastrointestinal tract cancer; $\mathrm{MM}$, multiple myeloma.

Table 2 Comparison of Primary Cancer Site Against Sex

\begin{tabular}{|c|c|c|c|c|}
\hline \multirow[t]{2}{*}{ Rank } & \multicolumn{2}{|l|}{ Female Patients } & \multicolumn{2}{|l|}{ Male Patients } \\
\hline & Current study & Shields et $\mathrm{al}^{12}(20 \mid 8)$ & Salcedo-Villanueva et al & Shields et al ${ }^{12}(20 \mid 8)$ \\
\hline I & Breast: 27 (62\%) & Breast: 4 I 3 (57.7\%) & Lung: 17 (48.5\%) & Lung: I64 (4I.4\%) \\
\hline 2 & Unknown: 6 (13.9\%) & Lung: I35 (I8.8\%) & GI: 7 (20\%) & Unknown: 91 (22.9\%) \\
\hline 3 & Ovary: 3 (6.9\%) & Unknown: 86 (I2.0\%) & Testicular: 3 (8.5\%) & Renal: 34 (8.5\%) \\
\hline 4 & Lung: 2 (4.6\%) & Others: 22 (3.0\%) & Renal: 3 8.3\%) & GI: 30 (7.5\%) \\
\hline 5 & Renal: 2 (4.6\%) & Lung carcinoid: 17 (2.3\%) & Prostate: 2 (5.7\%) & Prostate: 23 (5.8\%) \\
\hline 6 & Thyroid: 2 (4.6\%) & Renal: 12 (1.6\%) & Unknown: 2 (5.7\% & Melanoma: I9 (4.7\%) \\
\hline 7 & MM: I (2.3\%) & GI: 10 (I.3\%) & Carcinoid:I (2.8\%) & Others: 18 (4.5\%) \\
\hline 8 & & Melanoma: 8 (I.l\%) & & Thyroid: 9 (2.2\%) \\
\hline 9 & & Thyroid: 6 (0.8\%) & & Lung carcinoid: 7 (I.7\%) \\
\hline 10 & & Pancreas: 6 (0.8\%) & & Pancreas: 2 (0.5\%) \\
\hline
\end{tabular}

Abbreviations: MM, multiple myeloma; Gl, gastrointestinal tract cancer.

Table 3 Segmentation of Primary Cancer Site by Age

\begin{tabular}{|c|c|c|c|}
\hline & Age (SD) & Range & $95 \% \mathrm{Cl}$ \\
\hline Overall Patients N: 78 (100\%) & $57.62(14.52)$ & 23-87 & $54.35-60.94$ \\
\hline Breast: 27 & $56.85(14.4 I)$ & $26-87$ & $51.1-62.2$ \\
\hline Lung: 19 & $62.84(10.39)$ & $43-77$ & $57.82-67.85$ \\
\hline Unknown: 8 & $58(|3.5|)$ & $39-79$ & $46.7-69.29$ \\
\hline Gl tract: 7 & $56.28(16.27)$ & $28-80$ & $41.2-71.3$ \\
\hline Renal: 5 & $54.8(16.09)$ & $35-79$ & $34.8-74.7$ \\
\hline Testicular: 3 & $23.6(1.15)(P=0.002)$ & $23-25$ & $20.7-26.5$ \\
\hline Ovary: 3 & $56.33(4.72)$ & $51-60$ & $44.5-68.0$ \\
\hline Prostate: 2 & $67.5(0.70)$ & $67-68$ & $61.1-73.8$ \\
\hline Thyroid: 2 & $72.5(13.43)$ & $63-82$ & $-48.2-193.2$ \\
\hline Carcinoid: I & 82 & - & - \\
\hline MM: I & 62 & - & - \\
\hline
\end{tabular}

Abbreviations: SD, standard deviation; $95 \% \mathrm{Cl}$, ninety-five percent confidence intervals; Gl, gastrointestinal cancer; $\mathrm{MM}$, multiple myeloma.

cases: 87 and 85 years; 2) lung carcinoid, 82 years; 3) GI tract, 80 years; and 4) unknown, 79 years. The youngest cases observed were: 1) testicular, 3 cases: 23,23 , and 25 years; 2) breast, 26 years; and 3) GI tract, 28 years. To determine if there were differences between the groups oneway ANOVA was performed with a post hoc Tukey 
HSD analysis. Carcinoid and multiple myeloma cases were excluded since they only had one case each. Homogeneity of variances was first confirmed using Levene's test $(\mathrm{P}=0.217)$. Between groups ANOVA resulted in an $\mathrm{F}$ value of $3.421(\mathrm{P}=0.002)$, which confirms that at least one of the groups differs. Tukey HSD tests resulted in a statistical difference for Testicular cancer versus the rest of the primary cancer sites, except ovary cancer (breast: difference of 33.1 years, $\mathrm{P}=0.003$; lung: difference of 39.1 years, $\mathrm{P}=0.000$; unknown: difference of 34.3 years, $\mathrm{P}=0.007$; GI tract: difference 32.6 years, $\mathrm{P}=$ 0.016; renal: difference of 31.1 years, $\mathrm{P}=0.044$; prostate: difference of 43.8 years, $\mathrm{P}=0.13$; and thyroid: difference of 48.8 years, $\mathrm{P}=0.004)$.
A solitary lesion was observed in 56 cases (71.7\%), while multiple lesions were observed in 22 cases $(28.2 \%)$ (Figure 1A-D). Segmenting each primary cancer type, solitary lesions predominate in all groups except in testicular cancer, where multiple lesions were observed in 2 out of 3 patients $(66.6 \%)$. Unilateral metastasis were observed in 55 patients $(70.5 \%)$, while bilateral metastasis were present in 23 cases (29.4\%). Again, segmentation by primary cancer type revealed predominant unilateral lesions, except for testicular cancer, where bilateral metastasis was observed in 2 out of 3 patients $(66.6 \%)$. The single case of pulmonary carcinoid tumor had multiple lesions in one eye. The single case of multiple myeloma had solitary lesions in both eyes.
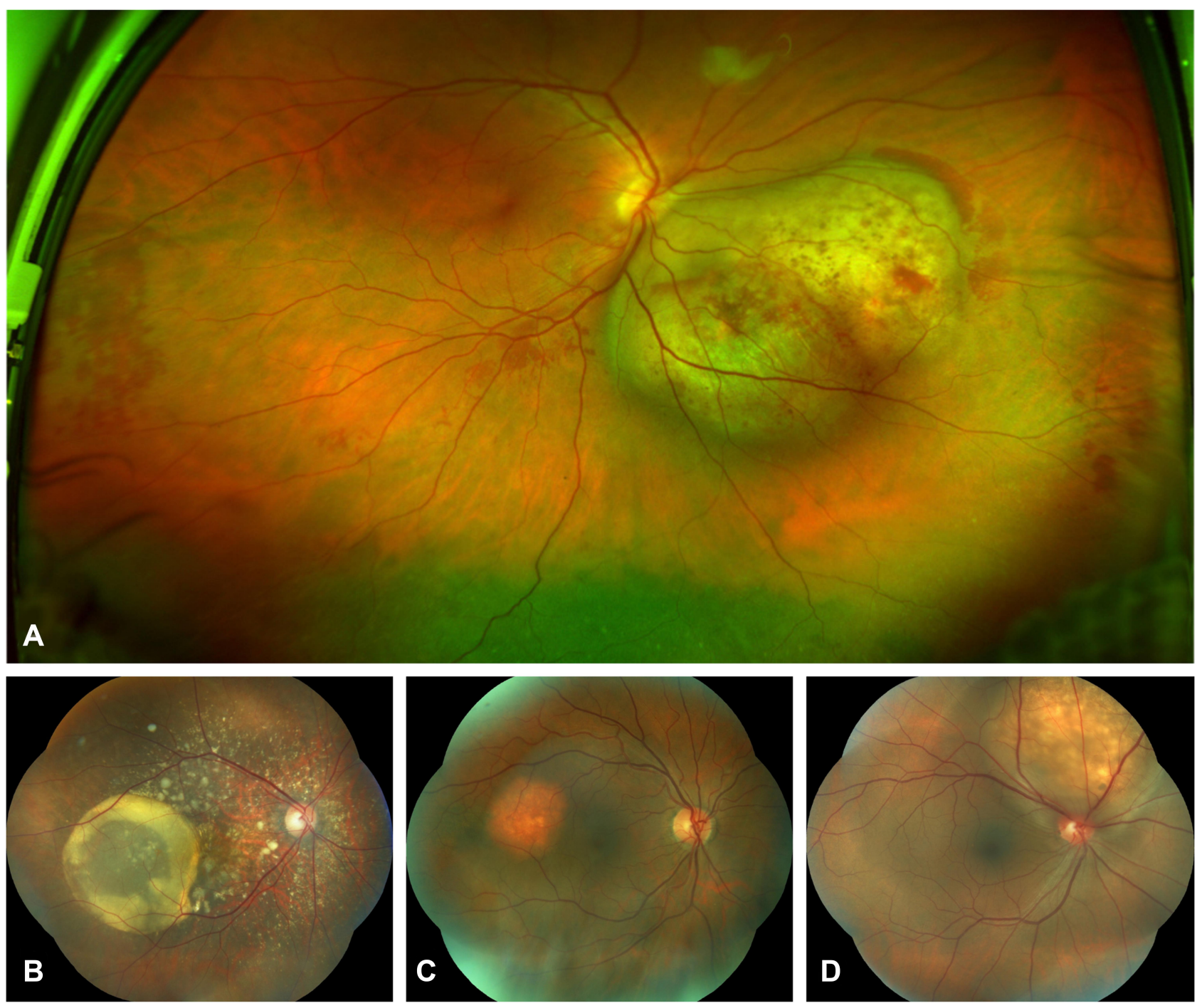

Figure I (A) Ultra-wide field fundus image of a single lesion, bi-lobulated, dome-shape choroidal metastasis from lung cancer, with intraretinal microhemorrhages over and around the tumor, as well as subretinal fluid in the lower retina quadrants. (B) Choroidal metastasis from breast cancer with multiple, disseminated seeds and a large cystoid subretinal fluid accumulation. (C) Renal cancer metastasis, reddish-orange, slightly elevated and round tumor. (D) Solitary, white-yellowish lesion from pulmonary cancer with subretinal fluid around the metastasis. 
From the complete sample of 78 choroidal metastasis, 48 cases $(61 \%)$ had a specific description of the color of the tumor. White-creamy lesions were observed in 30 cases (62.5\%); yellow lesions were observed in 12 cases $(25 \%)$; orange-red lesions were observed in 6 cases $(12.5 \%)$, from which, there was one case of an unknown primary cancer site, 3 cases of renal cancer, and 2 cases of thyroid cancer (Figure 1C).

Overall, the most common symptoms upon presentation were: decreased VA in 62 patients (79.4\%), floaters in 9 patients (11.5\%), scotoma in 4 patients $(5 \%)$, and pain in 3 patients (3.7\%). Patients were divided into the following groups based on VA: 1) good vision: from $20 / 20$ to $20 /$ 40 ; 2) moderate vision: from $20 / 50$ to $20 / 150$; and 3 ) bad vision: $<20 / 200$. Twenty-eight patients $(35.8 \%)$ presented good vision, 24 patients $(30.7 \%)$ presented moderate vision and 26 patients (33.3\%) presented bad vision.

The shapes described for the choroidal metastasis were dome $(\mathrm{n}=23,29.5 \%)$, flat $(\mathrm{n}=8,10.3 \%)$, round $(\mathrm{n}=7,9 \%)$, spots $(\mathrm{n}=2,2.6 \%)$, mushroom $(\mathrm{n}=1,1.3 \%)$, multi-lobulated $(\mathrm{n}=2,2.6 \%)$, and uni-lobulated $(\mathrm{n}=1,1.3 \%)$. The location on the posterior segment was nasal in $37 \%$, posterior pole in $26 \%$, temporal in $22 \%$, superior in $6 \%$, peripapillar in $5 \%$, inferior in $2 \%$, and diffuse in $2 \%$. Serous RD was observed in 48 patients $(61.5 \%)$. Location of the metastasis in relation to the macula was described in 59 out of 78 patients. Macular involvement were observed in 22 eyes (37.2\%). Extramacular involvement was observed in 37 cases $(62.7 \%)$.

Choroidal metastases as the first manifestation of cancer was found in 8 patients $(10.2 \%)$. The most common type of breast cancer was invasive ductal carcinoma; the most common type of lung cancer was small-cell carcinoma. Overall, the median time between cancer diagnosis and the identification of choroidal metastases was 12 months (range: $1.25-36$ months). The median time for breast cancer between cancer diagnosis and the presence of choroidal metastases was 45 months (range: 25-72 months). The median time for lung cancer between cancer diagnosis and presence of choroidal metastasis was 3 months (range: 1-10 months). Comparing the time for diagnosis of choroidal metastasis for these two subgroups (breast vs lung) using Mann-Whitney U-test resulted in a statistical significant difference $(\mathrm{P}<0.0001)$.

Choroidal metastases were treated with external beam radiation therapy in 18 patients (23\%), chemotherapy in 12 patients $(15.3 \%)$, plaque radiotherapy in 2 patients $(2.5 \%)$, photodynamic therapy in 2 patients $(2.5 \%)$, transpupillary thermotherapy in 1 patient $(1.2 \%)$, and intravitreal anti- vascular endothelial growth factor inhibitors (anti-VEGF) in 1 patient (1.2\%). Forty-two patients $(53.8 \%)$ were referred back to their oncology clinic for further work-up and treatment, while the rest were already under oncologist supervision.

\section{Discussion}

We presented the results of the first cohort of choroidal metastasis in a Latin American population, analyzed in Mexican patients over a period of 19 years. The primary cancer sites observed in our sample of patients have similarities and differences from the other major reports on the subject (Tables 1 and 2). Overall, the top 2 cancers that originate choroidal metastasis are breast and lung cancer, which corresponds to what has been previously reported by all cohorts; the American cohort from Shields et al, in their reports from 1997 and 2018; ${ }^{5,12}$ the German cohort by Kreusel et al from $2003 ;{ }^{10}$ and the Turkish cohort by Soysal from 2007. ${ }^{11}$ Breast and lung cancer are the predominant neoplasms in the world. Breast cancer had a worldwide incidence of 2,088,849 cases, and mortality of 626,679 cases in 2018; Lung cancer had a worldwide incidence of 2,093,876 cases, and mortality of 1,761,007 cases in 2018. In the USA breast and lung are the top two cancers; in Germany and Turkey they are the first and third (colorectum is second in Germany; prostate is second in Turkey). However, Mexico shows an important difference. Breast cancer is still the top cancer, with 27,286 cases and mortality of 6884 in 2018, but lung cancer occupies the 6th position, with an incidence of 7811 cases and mortality of 6733 cases in 2018 (prostate, colorectum, thyroid and cervix uteri are positioned before lung). ${ }^{2}$ Nonetheless, even if lung cancer is not as predominant in Mexico, the number of choroidal metastasis shown in our results indicate the high propensity for lung to metastasize and affect the uveal tract.

Not all cancers have the same propensity to generate metastasis. The highest frequencies for metastasis are observed in: 1) melanoma, 2) breast, 3) kidney, 4) neuroendocrine, and 5) lung, as reported by Budczies et al, ${ }^{14}$ in an analysis of 1008 autopsied patients. Ocular metastasis are not among the highest sites for cancer to metastasize. The top metastatic sites are the liver, non-regional lymph nodes, lungs, bones, and pleura, with eye involvement considered as "other metastatic sites" and occupying the 10th position. There are several hypothesis and factors involved on the mechanisms that lead to metastasis from a specific cancer type. ${ }^{15}$ However, besides tumor-specific 
metastatic rates, different cancers have entity-specific predilection sites for tumor expansion. As explained by Budczies et al, these may be attributable to the anatomical structure of vessels and blood flow as the underlying transport vehicle. For example, the choroid's high blood flow might be one of the leading factors that influence the possibility of metastasis, ${ }^{16}$ as well as its specific vessel architecture. $^{17}$ Therefore, a combination of a high worldwide incidence for breast and lung cancer, as well as a high propensity for the two cancers to disseminate metastasis, together with specific molecular and anatomical factors, make these two neoplasms the predominant primary cancer sites among different populations, including the latin cohort shown in our results.

The top third position for primary cancer site in our cohort was "unknown". This reflects the nature of our retrospective study were no follow-up analysis was performed throughout time. Therefore, there was no information on how many patients with choroidal metastasis and unknown cancer were accurately diagnosed at the end. This is well demonstrated by Kreusel et al, ${ }^{10}$ in their analysis of 71 consecutive patients, where 13 cases $(18 \%)$ initially had an unknown primary site, but at the end of follow-up only one case remained unknown (1\%). The information obtained from our results, as well as from the prior major reports, provides important knowledge as to where to look first for the primary site in unknown cases. Naturally, as explained before, the ophthalmologist should first suspect breast and lung cancer; however, if these primary sites are ruled-out, based on our results and depending on the the racial background and the gender of the patient, one could suspect on other etiologies. In female patients, ovary, renal and thyroid. In male patients, gastrointestinal tract, testicular, renal and prostate (Table 2). Shields et al, ${ }^{5}$ studied 142 cases with choroidal metastasis that had no history of primary cancer. Cancer remained unknown in $51 \%$ of that group of patients (73 cases). The primary cancers discovered for female patients were: lung ( 21 cases), breast (10 cases), GI tract (1 case), thyroid ( 1 case), bile duct ( 1 cases) and contralateral uveal melanoma (1 cases). For male patients they were: lung (29 cases), prostate, ( 2 cases), GI tract ( 1 case), skin melanoma ( 1 case), and pancreatic (1 case).

Another important clue that could help determine the primary cancer is the age at diagnosis. Based on our results, most choroidal metastasis are diagnosed at a mean age of 57.6 years, with a $95 \%$ CI from $54.35-$ 60.94 years. As expected, our population presented outliers, specifically some cases with younger age at presentation, such as testicular ( 3 cases with 23, 23 and 25 years, respectively), breast ( 1 case with 26 years), and GI tract ( 1 case with 28 years). It is important to consider that the only subgroup of cancer that showed a significant difference in age from the rest of the subgroups was testicular cancer with a mean age of 23.6 years. Testicular cancer is the most common cancer in men between 15 and 35 years, with a mean age of presentation of 33 years. ${ }^{18,19}$ Therefore, observing a possible choroidal metastasis in a young male patient should indicate the need to rule-out testicular cancer.

Besides the similarities previously mentioned among our cohort and the rest of the reports, some aspects differ when analyzing the rest of the subtypes of cancers in our population, which accounted for $30.7 \%$ of cases ( 24 patients). GI tract and renal cancer comprise the next possibilities, adding up together $15.3 \%$ of cases of choroidal metastasis observed in our results (GI tract: 7 cases [8.9\%]; renal: 5 cases [6.4\%]). These differ from the other cohorts: as reported by Shields et $\mathrm{al}^{12}{ }^{12}$ these two neoplasms accounted for $7.7 \%$ of the cases; by Kreusel et al, $6 \%$ of cases; and by Soysal, there was 1 case of GI tract cancer (3.6\%), and no renal cancer reported. By segmenting our results by gender (Table 2), GI tract cancer in male patients becomes the second most common primary site (20\% of cases), after lung cancer. Interestingly, no GI tract cancer was observed in female patients in our population. Cancer of the colorectum in Mexico had an incidence of 14,900 cases in 2018 (third top cancer in Mexico), while stomach cancer had an incidence of 7546 cases in the same year (7th top cancer in Mexico); in Germany, Turkey, and the USA colorectum is the fourth leading cancer.

Probably the most striking difference found in our results is the higher incidence of testicular metastasis (3 cases [3.8\%]) and ovarian metastasis (3 cases [3.8\%]). Testicular and ovarian cancer are not predominant neoplasms in the world; they account for approximately $1-2 \%$, and $3 \%$ of all cancers, respectively. Testicular cancer has shown a gradual increase in incidence. Among different countries and populations analyzed by Nigam et $\mathrm{al}^{18}$ hispanic men living in the USA presented an increased ratio of non-seminoma to seminoma, and the highest increase in incidence of testicular cancer in the USA. The authors attribute these observations to different gestational hormonal exposure, genetic susceptibility, and environmental exposures. Testicular cancer may present several clinical characteristics in the posterior segment of the eye. In a recent study by Barba-Navarrete et al, ${ }^{20}$ an 
ophthalmological analysis of 21 patients with testicular cancer was performed, where $48.7 \%$ of cases had some abnormality in the posterior segment not associated with other diseases. In their study, mean age at presentation was 29.7 years (18-43 years). Among the observed alterations, choroidal metastasis was present in 3 patients $(14.2 \%)$, retinal vascular tortuosity in 3 patients $(14.2 \%)$, pigmentary changes in 2 patients $(9.5 \%)$, and cancer associated retinopathy in 2 patients $(9.5 \%)$. While testicular cancer has shown an increasing incidence, the opposite is observed for ovarian cancer. The declining incidence observed for ovarian cancer in countries like the USA has been linked to the increasing exposure to oral contraceptives. $^{21}$ In an analysis of 75,000 cases of epithelial ovarian cancer the incidence rates declined over the last decade for non-hispanic whites, non-hispanic blacks and hispanic women in the USA. ${ }^{22}$ A plausible explanation for the different incidences observed among various ethnic groups could be the rates of oral contraceptive use; these rates were lower in hispanic women. ${ }^{23}$

An important observation to consider when diagnosing a choroidal metastasis is the color of the tumor. Interestingly, some metastasis, like those observed in renal cancer, might have an orange-red color instead of the classic white-creamy appearance. In our results, from the 3 cases of renal metastasis that included a description of the color, $100 \%$ presented an orange-red appearance. The reddish-orange appearance of these metastasis has been previously reported and could help differentiate these tumors. However, not all renal cancer metastasis have this reddish-orange color. Haimovici et $\mathrm{al}^{24}$ reported 5 cases of renal cell carcinoma, where 2 patients presented reddish-orange appearance, 2 had a lightly pigmented/whitish, and one had scattered creamy choroidal infiltrates. Thyroid cancer metastasis also showed an orangered color in the two cases observed in our results. This contrasts from the cohort reported by Shields et al, ${ }^{12}$ where only 1 patient with thyroid cancer metastasis out of 16 was reported as having "other" color/appearance.

The median time between the diagnosis of cancer and the choroidal metastasis secondary to breast cancer was 45 months. There are reported cases of late-onset choroidal metastases from breast cancer of more than 20 years after diagnosis of the primary tumor. ${ }^{25,26}$ The shortest time between the diagnosis of cancer and the choroidal metastases found in our study was for pulmonary cancer, again, explained by the aggressive nature of the disease, in which up to $56 \%$ of patients will have metastases at some point. ${ }^{27}$ Patients with choroidal metastases usually have a poor prognosis since metastatic disease usually appears in advanced stages of cancer. ${ }^{28}$ The outcome of 194 patients with choroidal metastasis due to lung cancer presented a mean interval from lung cancer diagnosis to death of 18 months (range 0-164 months), and from uveal metastasis diagnosis to death was 12 months (range $1-110$ months). ${ }^{29}$ Systemic survival rates for patients with uveal metastasis due to breast cancer in an analysis of 264 patients were $65 \%$ at 1 -year, $34 \%$ at 3 -year, and $24 \%$ at 5 -year follow-up. ${ }^{30}$

Due to poor prognosis, the treatment of choroidal metastasis is usually palliative. Indications for treatment include vision-threatening lesions, lesion enlargement despite systemic chemotherapy and painful lesions. ${ }^{31}$ External beam radiotherapy was the most common treatment in our study with 18 patients $(23 \%)$ treated this way. External beam radiotherapy has been considered an important alternative to treat choroidal metastases as it has proven to be an effective and safe palliative treatment. It helps to preserve or even improve vision, shrink tumors and, in unilateral cases, prevents contralateral eye disease. $^{31,32}$ Sometimes enucleation is necessary for blind, painful eyes. Other treatments that have proven to be effective in small case series are radioactive plaque brachytherapy, proton beam therapy, transpupillary thermotherapy and photodynamic therapy. ${ }^{31,33}$

In conclusions, we presented the first retrospective report on choroidal metastasis in a cohort of Latin American patients studied in Mexico. The retrospective nature of our study is its main weakness, providing a limited amount and sometimes incomplete data to be analyzed. Also, many of the participating sites are not general hospitals, so most patients were lost to follow-up, preventing further analysis on histopathology, treatments, survival rates, etc. Primary cancer sites and clinical features of choroidal metastasis in Mexican patients show similarities and differences from other populations; we found that, although breast and lung are the predominant sites in our population, our results show a higher proportion of gastrointestinal and renal cancer, as well as a higher incidence of ovarian and testicular cancer in comparison to other studies. These types of cancer, although not as common as breast or lung, need to be taken into account when studying Mexican patients living abroad. Cancer and choroidal metastasis have regional, racial and ethnic variations, which need to be considered when suspecting these life-threatening complications. A larger, multinational survey with other Latin American countries could help determine if the trends observed in our results repeat in other similar populations. 


\section{Ethics and Consent}

Ethical approval: This article does not contain any studies with human participants or animals performed by any of the authors. The study was approved by the ethics committee and research department prior to data collection.

Informed Consent: Information from this study was retrospective. However, all patients had informed consent signed for regular examinations.

\section{Funding}

No funding was received for this research by any of the authors or institutions.

\section{Disclosure}

The authors report no conflicts of interest for this work.

\section{References}

1. World Health Organization. The top 10 causes of death. Available from: https://www.who.int/news-room/fact-sheets/detail/the-top-10causes-of-death. Accessed May 20, 2019.

2. Global Cancer Observatory. World Health Organization. Available from: http://gco.iarc.fr. Accessed May 20, 2019.

3. International agency for research on cancer. World Health Organization. Available from: https://www.who.int/cancer/ PRGlobocanFinal.pdf. Accessed May 20, 2019.

4. Instituto Nacional de Estadística y Geografía. México. Available from: https//www.inegi.gob.mx. Accessed May 20, 2019.

5. Shields CL, Shields JA, Gross NE, Schwartz GP, Lally SE. Survey of 520 eyes with uveal metastases. Ophthalmology. 1997;104 (8):1265-1276. doi:10.1016/S0161-6420(97)30148-1

6. Shields CL, McMahon JF, Atalay HT, Hasanreisoglu M, Shields JA. Retinal metastasis from systemic cancer in 8 cases. JAMA Ophthalmol. 2014;132(11):1303-1308. doi:10.1001/jamaophthalmol. 2014.2406

7. Shields JA, Shields CL. Chapter 12. Metastatic tumors to the uvea, retina, and optic disc. In: Intraocular Tumors. An Atlas and Textbook. 3rd ed. Philadelphia: Lippincott, Wolters Kluwer; 2016.

8. Konstantinidis L, Damato B. Intraocular metastases - a review. Asia Pac J Ophthalmol. 2017;6(2):208-214. doi:10.22608/ APO.201712

9. Arepalli S, Kaliki S, Shields CL. Choroidal metastases: origin, features, and therapy. Indian J Ophthalmol. 2015;63(2):122-127. doi:10.4103/0301-4738.154380

10. Kreusel KM, Bechrakis N, Wiegel T, Emmerlich T, Foerster MH. Clinical characteristics of choroidal metastasis. Ophthalmologe. 2003;100(8):618-622. doi:10.1007/s00347-002-0768-9

11. Soysal HG. Metastatic tumors of the uvea in 38 eyes. Can J Ophthalmol. 2007;42(6):832-835. doi:10.3129/i07-155

12. Shields CL, Welch RJ, Malik K, et al. Uveal metastasis: clinical features and survival outcome of 2214 tumors in 1111 patients based on primary tumor origin. Middle East Afr J Ophthalmol. 2018;25(2):81-90. doi:10.4103/meajo.MEAJO_6_18

13. U.S. Census Bureau. American community survey 1-year estimates; 2017. Available from: https://factfinder.census.gov/faces/tableser vices/jsf/pages/productview.xhtm1?pid=ACS_17_1YR_ B03001\&prodType=table. Accessed May 20, 2019.
14. Budczies J, von Winterfeld M, Klauschen F, et al. The landscape of metastatic progression patterns across major human cancers. Oncotarget. 2015;6(1):570-583. doi:10.18632/oncotarget.2677

15. Liu Q, Zhang H, Jiang X, et al. Factors involved in cancer metastasis: a better understanding to "seed and soil" hypothesis. Mol Cancer. 2017;16(1): 176

16. Weiss L. Analysis of the incidence of intraocular metastasis. $\mathrm{Br}$ J Ophthalmol. 1993;77:149-151. doi:10.1136/bjo.77.3.149

17. McCartney A. Intraocular metastasis. Br J Ophthalmol. 1993;77 (3):133. doi:10.1136/bjo.77.3.133

18. Nigam M, Aschebrook-Kilfoy B, Shikanov S, Eggener S. Increasing incidence of testicular cancer in the United States and Europe between 1992 and 2009. World J Urol. 2015;33(5):623-631. doi:10.1007/s00345-014-1361-y

19. American Cancer Society. About Testicular Cancer. Available from: https://www.cancer.org/cancer/testicular-cancer/about/key-statistics. html\#references. Accessed May 20, 2019.

20. Barba-Navarrete DM, Moreno-Páramo D, Corona-Montes VE, et al. Ophthalmological changes of the posterior segment in patients with testicular cancer in a mixed-race population of the General Hospital of Mexico. Arch Soc Esp Oftalmol. 2018;93(9):417-422. doi:10.1016/j.oftal.2018.05.004

21. Sopik V, Iqbal J, Rosen B, Narod SA. Why have ovarian cancer mortality rates declines? Part I. Incidence Gynecol Oncol. 2015;138:741-749. doi:10.1016/j.ygyno.2015.06.017

22. Park HK, Ruterbusch JJ, Cote ML. Recent trends in ovarian cancer incidence and relative survival in the United States by race/ethnicity and histologic subtypes. Cancer Epidemiol Biomarkers Prev. 2017;26 (10):1511-1518. doi:10.1158/1055-9965.EPI-17-0290

23. Jones J, Mosher W, Daniels K. Current contraceptive use in the United States, 2006-2010, and changes in patterns of use since 1995. Natl Health Stat Report. 2012;60:1-25.

24. Haimovici R, Gragoudas ES, Gregor Z, et al. Choroidal metastases from renal cell carcinoma. Ophthalmology. 1997;104(7):1152-1158. doi:10.1016/S0161-6420(97)30169-9

25. Randhawa S, Johnson RN. Choroidal metastases 34 years after remission of breast cancer. Retin Cases Brief Rep. 2015;9(1):25-29. doi:10.1097/ICB.0000000000000069

26. Levinson A, Erenler F, Zhao Y, et al. Late-onset choroidal metastasis from breast cancer. Retin Cases Brief Rep. 2018;12(4):342-345. doi:10.1097/ICB.0000000000000516

27. Riihimäki M, Hemminki $\mathrm{A}$, Fallah $\mathrm{M}$, et al. Metastatic sites and survival in lung cancer. Lung Cancer. 2014;86(1):78-84. doi:10. 1016/j.lungcan.2014.07.020

28. Ratanatharathorn V, Powers WE, Grimm J, et al. Eye metastasis from carcinoma of the breast: diagnosis, radiation treatment and results. Cancer Treat Rev. 1991;18:261-276. doi:10.1016/0305-7372(91)90017-T

29. Shan SU, Mashayekhi A, Shields CL, et al. Uveal metastasis from lung cancer: clinical features, treatment, and outcome in 194 patients. Ophthalmology. 2014;121(1):352-357. doi:10.1016/j.ophtha.2013.07. 014

30. Demirci H, Shields CL, Chao AN, Shields JA. Uveal metastasis from breast cancer in 264 patients. Am J Ophthalmol. 2003;136 (2):264-271. doi:10.1016/S0002-9394(03)00192-2

31. Kanthan GL, Jayamohan J, Yip D, Conway RM. Management of metastatic carcinoma of the uveal tract: an evidence-based analysis. Clin Exp Ophthalmol. 2007;35(6):553-565. doi:10.1111/j.14429071.2007.01550.x

32. Wiegel T, Bottke D, Kreusel KM, et al. External beam radiotherapy of choroidal metastases - final results of a prospective study of the German Cancer Society (ARO 95-08). Radiother Oncol. 2002;64 (1):13-18. doi:10.1016/S0167-8140(02)00134-2

33. Konstantinidis L, Rospond-Kubiak I, Zeolite I, et al. Management of patients with uveal metastases at the liverpool ocular oncology centre. Br J Ophthalmol. 2014;98(1):92-98. 


\section{Publish your work in this journal}

Clinical Ophthalmology is an international, peer-reviewed journal covering all subspecialties within ophthalmology. Key topics include: Optometry; Visual science; Pharmacology and drug therapy in eye diseases; Basic Sciences; Primary and Secondary eye care; Patient Safety and Quality of Care Improvements. This journal is indexed on PubMed

Submit your manuscript here: https://www.dovepress.com/clinical-ophthalmology-journal
Central and CAS, and is the official journal of The Society of Clinical Ophthalmology (SCO). The manuscript management system is completely online and includes a very quick and fair peer-review system, which is all easy to use. Visit http://www.dovepress.com/ testimonials.php to read real quotes from published authors. 